\title{
Nutrigenetic testing and personalised nutrition: a qualitative study
}

\author{
J. Richardson and V. Mason \\ Institute of Health and Society, Worcester University, Henwick Grove, Worcester WR2 6AJ, UK
}

Genetic differences between individuals can affect metabolic processes and nutrient requirements ${ }^{(1)}$. Some of these genetic differences involve alterations of individual nucleotides in the DNA sequence (SNP). Nutrigenetic tests can screen the DNA of individuals to identify SNP that may affect disease risk $^{(2)}$. Several commercial companies already offer nutrigenetic tests direct to consumers or through health practitioners and results may be linked to nutritional advice to reduce disease risk. Many authors have questioned the validity and reliability of these tests ${ }^{(3,4,5,6,7)}$.

Nutritional therapy is a complementary therapy that offers individualised holistic nutritional advice to patients in order to optimise their health. There is growing interest among nutritional therapists (NT) in using commercially available nutrigenetic tests to inform personalised dietary advice. The use of these tests within nutritional therapy practice already occurs and is expected to rise (McGinty S, unpublished results). This study aims to explore the views of NT about the use of nutrigenetic tests using a qualitative approach.

Ethical approval was obtained from the University of Worcester. Semi-structured interviews were conducted with NT ( $n$ 10). The interviews were audio-recorded and transcribed verbatim. The transcript of each data item was read and re-read. Codes were identified inductively and data were assigned to them ${ }^{(8)}$. A thematic map was generated and codes were aggregated into themes; the effects of nutrigenetic tests on consultations, patient motivation and compliance, counselling requirements, test reliability and validity, public health implications, nutritional therapy education and practice boundaries.

The findings suggest that NT believed that nutrigenetic tests would not have a great impact on consultations as they would only form one part of a holistic assessment and that advice currently given would protect against major chronic diseases. There was a view that most patients would not choose to take a nutrigenetic test due to cost and because tests are pre-emptive and people are unlikely to take them while they are healthy. Test results and personalised nutrition advice were expected to affect patient motivation and compliance but could have positive and negative effects. NT emphasised the importance of pre- and post-test counselling to ensure that patients were well supported and advised. The reliability and validity of the tests was a concern for some NT in the study. Some did not feel that nutrigenetic tests should be offered by NT. Concerns about the implications of nutrigenetic testing on wider issues such as public health were also expressed.

Most NT who participated in this study did not feel confident in the use of nutrigenetic tests but felt that such tests would become more widely used in the future. Practitioner education should embrace the controversies and debate about nutrigenetic testing and personalised nutrition, to facilitate NT contribution to research and evidence based practice.

1. Brown L \& van der Ouderaa F (2007) Br J Nutr 97, 1027-1035.

2. Kraft P \& Hunter DJ (2009) N Engl J Med 360, 1701-1703.

3. Arab L (2004) Proc Nutr Soc 63,167-172.

4. Afman L \& Muller M (2006) J Am Diet Assoc 106, 569-576.

5. Gillies PJ \& Krul ES (2007) J Nutr 137, 270S-274S.

6. Joost HG, Gibney MJ, Cashman KD et al. (2007) Br J Nutr 98, 26-31.

7. Janssens ACJW, Gwinn M, Bradley LA et al. (2008) Am J Hum Genet 82, 593-599.

8. Braun V \& Clarke V (2006) Qual Res Psychol, 3, 77-101. 